\title{
Improved diagnosis of farmer's lung using the fluorescent antibody technique
}

\author{
G. B O Y D a n d D. PAR R A T \\ Centre for Respiratory Investigation, Glasgow Royal Infirmary and the University Department \\ of Bacteriology and Immunology, Western Infirmary, Glasgow
}

\begin{abstract}
Boyd, G. and Parratt, D. (1974). Thorax, 29, 417-420. Improved diagnosis of farmer's lung using the fluorescent antibody technique. In the west of Scotland 20 of 40 farmers surveyed had symptoms of farmer's lung. Ten of this group $(50 \%)$ gave positive precipitin reactions to Micropolyspora faeni. The fluorescent antibody test was positive in all those with symptoms and also in one who had no clinical evidence of farmer's lung. There was a close relationship between evidence of sensitization to $M$. faeni in the serum, demonstrated by the fluorescent antibody test, and the presence of symptoms compatible with farmer's lung. This test may detect the disease in milder form than is possible by conventional precipitin tests and this study confirms the value of this more sensitive technique as a screening procedure.
\end{abstract}

Farmer's lung is a well recognized clinical syndrome which results from a hypersensitivity reaction similar to the type III or Arthus type in the lungs and which occurs in sensitized subjects following exposure to certain thermophilic actinomycetes and to Micropolyspora faeni in particular (Pepys, 1969). Serological confirmation of the diagnosis has rested largely on the demonstration of precipitin reactions by Ouchterlony double diffusion methods or immunoelectrophoresis (Pepys and Jenkins, 1965). Latex agglutination (Murray, Pepys, and Brighton, 1967) and complement fixation (Public Health Laboratory Service Working Party, 1967) have been employed but have been shown to hold little advantage over the precipitin tests. The presence of precipitin reactions has been shown to correlate with a history of attacks of farmer's lung (Pepys and Jenkins, 1965; Hapke et al., 1968) and the intensity of the precipitin reaction correlated to some degree with the severity of the disease (Pepys and Jenkins, 1965). These studies supported the view that the presence of precipitins is related to clinical disease. There is also a large group with clinical symptoms of type III hypersensitivity following exposure to mouldy hay who do not show precipitin reactions in the sera. This was demonstrated in a recent survey in different areas in Scotland (Grant et al., 1972) and it appears that the demonstration of precipitins is an insensitive way of confirming the clinical evidence of farmer's lung. A new serological approach has been described recently (Parratt and Peel, 1972) and this affords a more sensitive serological confirmation of the clinical diagnosis.

This paper reports the results of a survey carried out on a group of farmers in the west of Scotland and demonstrates the value of this new technique in the improved diagnosis of farmer's lung.

\section{MATERIALS AND METHODS}

Forty farm workers from 26 farms in the west of Scotland who handled hay during their daily routine were studied. They were drawn largely from an unselected group within the practice of a single general practitioner and 13 were referred from other sources to the Centre for Respiratory Investigation at Glasgow Royal Infirmary for assessment. Their ages ranged from 14 to 65 years with a mean of $43 \cdot 3$ years. Thirty were male and 10 were farmers' wives. In addition, a small group of four former farm workers was investigated. They had all left farming for periods ranging from two to five years as a result of acute farmer's lung.

DOCUMENTATION A clinical history of respiratory symptoms was taken in each case using the Medical Research Council questionnaire for chronic bronchitis and a second questionnaire designed to elicit symptoms of hypersensitivity of the Arthus type following 
T A B L E I

PREVALENCE OF SYMPTOMS AND OF POSITIVE SEROLOGICAL TESTS IN FARM WORKERS

\begin{tabular}{|c|c|c|c|c|c|}
\hline & No. & Age Range & Symptoms & Precipitin & FAT \\
\hline $\begin{array}{l}\text { Male } \\
\text { Female }\end{array}$ & $\begin{array}{l}30 \\
10\end{array}$ & $\begin{array}{l}14-65(\text { mean } 42 \cdot 4) \\
31-61(\text { mean } 46 \cdot 0)\end{array}$ & $\begin{array}{r}17 \\
3\end{array}$ & $\begin{array}{l}8 \\
2\end{array}$ & $\begin{array}{r}18 \\
3\end{array}$ \\
\hline Total & 40 & $14-65($ mean $43 \cdot 3)$ & $20(50 \%)$ & $10(25 \%)$ & $21(52.5 \%)$ \\
\hline
\end{tabular}

FAT $=$ fluorescent antibody test.

exposure to mouldy hay, straw or grain. A history of shortness of breath, usually associated with a dry cough with or without episodes of pyrexia which developed or were aggravated some hours following exposure to mouldy hay, straw or grain, was accepted as symptomatic evidence of farmer's lung. The occurrence of wheeze immediately on exposure did not preclude the diagnosis provided that the other criteria were met.

SEROLOGICAL EXAMINATION A venous blood sample was taken for serological examination. This was divided into several aliquots which were stored at $-20^{\circ} \mathrm{C}$ until analysed. Conventional precipitin tests employing the Ouchterlony double diffusion technique using two aqueous extracts of $M$. faeni were carried out in each case. The fluorescent antibody test was performed according to the method of Parratt and Peel (1972). Patients' sera were diluted 1:50 with sterile saline and reacted with a slide culture of $M$. faeni in the first stage of the procedure. After washing with phosphate-buffered saline ( $\mathrm{pH} \mathrm{7 \cdot 2)}$ the antibody absorbed on to the surface of the $M$. faeni was detected using a fluorescein-labelled antihuman globulin after exposure to ultraviolet light.

\section{RESULTS}

Table I summarizes the findings in the 40 farm workers who were studied. Twenty had symptoms in keeping with the diagnosis of farmer's lung and, as expected, there was a higher prevalence among males. Of the 20 with symptoms, 10 gave positive precipitin reactions in their sera. All had a positive reaction in the fluorescent antibody test. One patient with a clinical history of chronic bronchitis associated with chest deformity but with no symptoms suggestive of farmer's lung had a positive reaction in the fluorescent antibody test.

Table II summarizes the main symptoms recorded in 20 clinical cases. Dyspnoea after exposure to mouldy hay was a constant feature and in $75 \%$ symptoms were also experienced after handling mouldy grain. This was particularly noticeable during the bruising or milling processes when feed was being prepared for the cattle. Dry cough, episodes of fever or shivering, and excessive tiredness several hours after exposure were common but not constant findings in all. In those subjects with positive precipitins these symptoms were more marked, and dyspnoea after exposure to hay followed by shivering and/or pyrexia together with feelings of excessive tiredness occurred in all. Eighty per cent were also aware of a dry $\vec{V}$ irritating cough. Those with negative precipitin 음 reactions had less marked findings. All had increased breathlessness after exposure to mouldy $\complement$ hay but this was followed by less constant features; some reported fever and shivering, others $\overrightarrow{0}$ tiredness, and a lower percentage complained of $\underset{ }{D}$ dry cough.

Wheeze and rhinitis were not prominent features.

Seven $(35 \%)$ of the symptom-positive group satisfied the MRC criteria for chronic bronchitis 응 although only two were smokers. In the remaining $\varrho$ subjects without symptoms of farmer's lung, only 흠 two $(10 \%)$ gave histories of chronic bronchitis, one a heavy smoker and one with kyphoscoliosis and long-standing respiratory trouble. In the small group of former farm workers (Table III) who had been away from farming on average for $3.75 \frac{\text { 응 }}{2}$ years, persistent symptoms were found in two. $\times$ Both had radiological evidence of pulmonary 3 fibrosis and clinical evidence of chronic respiratory failure. Although known to have been present $\frac{\text { 을 }}{3}$ during the initial illnesses, precipitins were negative in all four although one, a man who had been away from farming for only two years, the $\frac{D}{O}$

T A B L E I I SYMPTOMS IN 20 CLINICAL CASES

\begin{tabular}{|c|c|c|c|c|c|c|}
\hline & \multicolumn{2}{|c|}{ Total 20} & \multicolumn{2}{|c|}{$\begin{array}{l}\text { Precipitin } \\
+ \text { ve (10) }\end{array}$} & \multicolumn{2}{|c|}{$\begin{array}{l}\text { Precipitin } \\
\text { - ve (10) }\end{array}$} \\
\hline & No. & $\%$ & No. & $\%$ & No. & $\%$ \\
\hline $\begin{array}{l}\text { Dyspnoea after } \\
\text { mouldy hay }\end{array}$ & 20 & 100 & 10 & 100 & 10 & 100 \\
\hline $\begin{array}{l}\text { barley } \\
\text { Dry cough } \\
\text { Fever/shivering } \\
\text { Tiredness } \\
\text { Wheeze } \\
\text { Rhinitis } \\
\text { Chronic bronchitis } \\
\text { Persistent winter }\end{array}$ & $\begin{array}{r}15 \\
16 \\
14 \\
16 \\
16 \\
5 \\
4 \\
7\end{array}$ & $\begin{array}{l}75 \\
80 \\
70 \\
80 \\
25 \\
20 \\
35\end{array}$ & $\begin{array}{r}8 \\
8 \\
10 \\
10 \\
1 \\
0 \\
4\end{array}$ & $\begin{array}{r}80 \\
80 \\
100 \\
100 \\
10 \\
\frac{40}{10}\end{array}$ & $\begin{array}{l}7 \\
8 \\
4 \\
6 \\
4 \\
4 \\
3\end{array}$ & $\begin{array}{l}70 \\
80 \\
40 \\
60 \\
40 \\
40 \\
30\end{array}$ \\
\hline $\begin{array}{l}\text { colds } \\
\text { Weight loss }\end{array}$ & $\begin{array}{l}9 \\
4\end{array}$ & $\begin{array}{l}45 \\
20\end{array}$ & $\begin{array}{l}5 \\
3\end{array}$ & $\begin{array}{l}50 \\
30\end{array}$ & $\begin{array}{l}4 \\
1\end{array}$ & $\begin{array}{l}40 \\
10\end{array}$ \\
\hline
\end{tabular}


T A B L E I I I

INCIDENCE OF POSITIVE TESTS AMONG FORMER FARM WORKERS WHO GAVE UP FARMING BECAUSE OF FARMER'S LUNG

\begin{tabular}{c|c|c|c|c}
\hline No. & Years away from Farming & Persistent Symptoms & Positive FAT & Positive Precipitin \\
\cline { 1 - 4 } & 5-2 (mean 3-75) & 2 & 1 & 0 \\
\hline
\end{tabular}

shortest period of the group, gave a positive fluorescent antibody test.

\section{DISCUSSION}

A recent epidemiological survey of farmers in Scotland (Grant et al., 1972) suggested that a high percentage of those with clinical symptoms of farmer's lung have negative serology as determined by conventional precipitin tests. Even if one accepts the traditional view that the diagnosis is only valid when the FLH precipitin test is positive, the prevalence rates for the condition that these workers reported in two of the areas they studied, Orkney and Ayrshire, are still more than 20 times higher than any figure previously reported in Britain and the authors stress that the prevalence of farmer's lung has so far been seriously underestimated. The development of a fluorescent antibody test in the diagnosis of farmer's lung (Parratt and Peel, 1972) adds weight to this argument since not only those with precipitins to $M$. faeni give positive reactions in the fluorescent antibody test but also those with clinical symptoms of the disease who do not give positive precipitin reactions in their sera.

In this present study, 20 of the 40 included in the survey had symptoms of farmer's lung. Ten of this group $(50 \%)$ gave positive precipitins on conventional testing against two extracts of $M$. faeni and this test correlated poorly with the clinical symptoms in the group as a whole. The fluorescent antibody test, however, was positive in all those with symptoms. Of the remainder who had no symptoms in keeping with farmer's lung, none had positive precipitin reactions and only one gave a positive fluorescent antibody test. $\mathrm{He}$ was a poor historian with congenital kyphoscoliosis and a moderate chest deformity who had had symptoms of chronic bronchitis since childhood. During the winter months of recent years his respiratory symptoms were more severe, dyspnoea increasing to grade III severity, and it is possible that the more obvious symptoms of farmer's lung were obscured by those of his chest deformity and associated chronic inflammatory disease. These results show a close relationship between symptoms and the demonstration of circulating antibody to $M$. faeni by the fluorescent antibody test and they confirm that this test is much more sensitive than conventional precipitin tests as an indicator of sensitization to this organism.

Among those with clinical symptoms, the 10 with precipitins had more symptoms than those who gave positive reactions only in the fluorescent antibody test. The precipitin-positive group all complained of dyspnoea some time after exposure to mouldy hay or barley, most with an associated dry cough and all with fever, shivering, severe lassitude, and lack of energy. In those with symptoms who gave positive reactions to the fluorescent antibody test only, all suffered dyspnoea following exposure but although dry cough occurred with similar frequency, the frequency of fever, shivering bouts, and complaints of lassitude and tiredness was less than in those with precipitins. This suggests that those with precipitins had more severe clinical disease than those without and that those with the milder symptoms had evidence of hypersensitivity to $M$. faeni with circulating antibody in their sera detectable by the fluorescent antibody test but not present in sufficient quantity to permit a precipitin reaction to be demonstrated in gel diffusion. This test, therefore, may be able to detect the disease in milder forms than is possible by conventional precipitin tests and may therefore play an important part along with increased clinical awareness of the condition to afford improved and earlier recognition of farmer's lung. The findings in the four subjects who had left farming confirmed previous reports (Hapke et al., 1968) that precipitin reactions become negative after about three years. The fluorescent antibody tests, too, were negative in three of the four. Once exposure ceases, the amount of circulating antibody slowly falls and in this small group the levels were undetectable in those who had left the industry three or more years ago.

In our experience most farmers tend to minimize symptoms of illness and to ignore minor ailments since they have to keep working in order that their farm and livelihood may survive. Frequently, it is only when symptoms seriously impair or actually prevent a farmer from carrying 
out his daily routines that he seeks medical aid. Minor and even moderate symptoms are tolerated or often ignored so that it is only by careful and detailed interviewing that a true assessment of the subjects' symptoms can be obtained. Pepys and Jenkins (1965) reported positive precipitin reactions in $19 \%$ of 28 'normal' farmers in a study of typical acute attacks of farmer's lung. In a later paper (Hapke et al., 1968) this was reduced to one positive reaction out of 42 subjects in whom a history of respiratory symptoms suggestive, as well as typical, of farmer's lung had been rigorously excluded. In this present series, where mild symptoms suggestive of farmer's lung were sought by personal interview and by use of a detailed questionnaire, the fluorescent antibody test was negative and no positive precipitin reactions were recorded in 20 asymptomatic subjects. It seems likely that the high percentage of precipitin reactions reported by earlier workers reflects a different approach to documentation of symptoms, especially of the milder forms of the disease. Evidence of chronic bronchitis was commoner in those with symptoms of farmer's lung than in those without, even after taking smoking habits into account, and it may be unwise, therefore, to exclude or ignore less specific respiratory symptoms when assessing symptomatology in relation to farmer's lung.

This study demonstrates the close relationship between evidence of sensitization to $M$. faeni and the presence of symptoms of farmer's lung. In the light of these findings, the presence of raised antibody levels to this organism in a patient's serum is evidence that the individual is at risk to the symptoms of farmer's lung, the severity being related, in part, to the amount of circulating antibody present. A positive fluorescent antibody test, however, merely indicates the presence of an amount of circulating antibody which in the small group studied and in those cases reported previously (Parratt and Peel, 1972) is closely related to the occurrence of symptoms. It does not necessarily follow that all subjects with a positive fluorescent antibody test must have symptoms of farmer's lung but only that they show significant sensitization to $M$. faeni and therefore are likely to develop them. With wider application of this test it is to be expected that positive reactions will be found in some asymptomatic subjects. Such $\overrightarrow{\overrightarrow{\mathrm{S}}}$ individuals would be at risk to symptoms ofo farmer's lung and it would be prudent to considero simple preventive measures such as using a maske in these circumstances.

This study confirms the value of the fluorescento antibody test as a screening procedure for the detection of those workers at risk in the farming $\vec{\circ}$ population. This should therefore allow earlier $\overrightarrow{\vec{H}}$ treatment and permit preventive measures to beo instituted in affected farm workers and thereby reduce the hazard of the allergic reaction in the lungs progressing to chronic irreversible damage with fibrosis and destruction of lung parenchyma:

We are grateful to Professor $R$ G. White and to Dr. F. Moran for their interest and helpful advice. We are indebted to Dr. W. M. Jamieson, of Beith for arranging access to his patients and for his valuable support with the field work.

\section{REFERENCES}

Grant, I. W. B., Blyth, W., Wardrop, V. E., Gordon R. M., Pearson, J. C. G., and Mair, A. (1972) Prevalence of farmer's lung in Scotland. A pilot survey. British Medical Journal, 1, 530.

Hapke, E. J., Seal, R. M. E., Thomas, G. O., Hayes, M., and Meek, J. C. (1968). Farmer's lung. $A \vec{F}$ clinical, radiographic, functional, and serologica correlation of acute and chronic stages. Thorax 23, 451 .

Murray, I. G., Pepys, J., and Brighton, W. D. (1967) The latex agglutination test in farmer's lung. Monthly Bulletin of the Ministry of Health and the Public Health Laboratory Service, 26, 96.

Parratt, D. and Peel, J. A. (1972). A fluorescent antibody test in the diagnosis of farmer's lung? Journal of Clinical Pathology, 25, 846.

Pepys, J. (1969). Hypersensitivity diseases of the lungs due to fungi and organic dusts. Monographs in Allergy, Vol. 4. Karger, Basel.

- and Jenkins, P. A. (1965). Precipitin (F.L.H.) test in farmer's lung. Thorax, 20, 21 .

Public Health Laboratory Service Working PartyN (1967). The complement-fixation test in farmer's lung. Monthly Bulletin of the Ministry of Health and the Public Health Laboratory Service, 26 이
167.

Requests for reprints to: Dr. G. Boyd, Centre for: Respiratory Investigation, the Royal Infirmary, Glasgow. 